\title{
Experimental Investigation on Multi-Stage Downdraft Gasification: Influence of Air Ratio and Equivalent Ratio to the Gasifier Performance
}

\author{
Arif Rahman Saleh ${ }^{1,2}$ a) Bambang Sudarmanta ${ }^{3, \text { b) }}$ \\ ${ }^{1,}$ Doctoral Student of Mechanical Engineering Department, Faculty of Industrial and Technology, \\ Institut Teknologi Sepuluh November, Surabaya. \\ ${ }^{2}$ Department of Mechanical Engineering, Faculty of Engineering \\ Universitas Pasir Pengaraian, Riau \\ ${ }^{3}$ Department of Mechanical Engineering, Faculty of Industrial and Technology, \\ Institut Teknologi Sepuluh November, Surabaya. \\ a) Corresponding author: ariefrahmansaleh@gmail.com \\ b) sudarmanta@me.its.ac.id
}

\begin{abstract}
Multi-stage gasification process adding multiple air injection (at pyrolysis and oxidation) to reduce tar content and improve the efficiency. all components of the fuel can decompose perfectly into pyrolysis products and the total pyrolysis product also increases. The mean temperatures in the pyrolysis zone are respectively between $569^{\circ} \mathrm{C}$ and $633^{\circ} \mathrm{C}$ for the $0 \%$ and $90 \%$ Air Ratios. Temperature increases in the pyrolysis zone change the nature of the endothermal into exothermal and providing the heat energy for the drying, oxidation and reduction zones. While the temperature of the partial oxidation zone reaches $858^{\circ} \mathrm{C}$. For a total air flow of $10.5 \mathrm{Nm}^{3} / \mathrm{h}$ with a $90 \%$ air ratio, the gasifier can produce a low tar content of $32.27 \mathrm{mg} / \mathrm{Nm}^{3}$ when compared to $0 \%$ air ratio of $106.5 \mathrm{mg} / \mathrm{Nm}^{3}$. This result shown that multi-stage gasifier can reduce tar content by $30 \%$.
\end{abstract}

\section{INTRODUCTION}

Biomass gasification for power generation faces many difficulties when entering commercialization scale [1] due to various problems, especially from the beginning of the fuel handling [2], biomass conversion technique to gas [3, 4] methods of gas cleaning (dry gas), gas cooling and methods of utilization of gas into electrical energy [5, 6]. Gasification applications in internal combustion engines require syngas with tar amounts about $10-50 \mathrm{mg} / \mathrm{Nm}^{3}$ [7]. Meanwhile, tar produced in the conventional downdraft gasifiers about $2 \mathrm{~g} / \mathrm{Nm}^{3}$ and conventional updraft gasifier is about $58 \mathrm{~g} / \mathrm{Nm}^{3}$. If the applied system of cleaning supplies gas with high efficiency, then the content of tar will be reduced to approximately $20-40 \mathrm{mg} / \mathrm{Nm}^{3}$ and the content of tar will be less than the specified level, but required higher costs and requires the installation of a wide system [8]. The gas cleaning system also produces liquid waste including carcinogenic elements and requires extensive treatment before disposal. Furthermore, if the gas is used on diesel engine that will cause operational problems due to a blockage in the air intake and abnormal wear on the engine components [21]. Due to the many technical problems, especially on the gas cleaning unit and the ash problem many large-scale gasification for the power plant has been cancelled [9]. Therefore, as much as possible tar should be removed from syngas.

The methods used to eliminate tar levels can be divided into two ways: primary and secondary methods [10]. In the primary method, the cleaning process takes place inside the gasifier, and on the secondary method the gas is handled after exiting the gasifier by adding handling equipment. The primary method of the procedure is to prevent or convert tar formed in a gasifier, meaning appropriate operating conditions, using a catalyst layer or modifying the reactor's physical configuration. The secondary method is a method in which tar is handled after a physical gasifier 
or chemical process. Therefore, the primary method for tar cleaning is combined with thermal cracking, a multistage gasification system developed, which is based on injection of the gasification agent and the addition of the site from the combustion zone as for example the pyrolysis zone leads to Partial oxidation in this region resulting in high gas concentrations and very small tar content [11].

The primary method by modifying the gasifier structure of a single air input into multi-stage air input has been done by some of the earlier studies of Sudarmanta [22,23] which examined the effect of two air input positions and varied the type of gasification agent used. The results of Bui's research [24] reported that the maximum temperature was reached in the second zone (pyrolysis). Furthermore, tar content in syngas 40 times lower when compared with single-stage conditions (from $3600 \mathrm{mg} / \mathrm{Nm}^{3}$ to $92 \mathrm{mg} / \mathrm{Nm}^{3}$ ). The increase in cold gas efficiency also occurred from $86-90 \%$ to $92-97 \%$ [26]. In addition to modifying the structure of the gasifier, Bentzen [26] added a layer of charcoal to the oxidation zone to reduce the tar content to $15 \mathrm{mg} / \mathrm{Nm}^{3}$. Premixed between gasifying agent and syngas was also performed on two-stage gasifiers to improve gas quality and reduce tar content to obtain an increase of $\mathrm{H}_{2}$ content in syngas by $20 \%$ and temperature rise in pyrolysis zone between $725-954^{\circ} \mathrm{C}$. Multi-stage gasifier modified by Antonopolous [25] adding physical grate to separate pyrolysis and oxidation zones, the modifications produce gasifiers that can be used for different types of fuel. The maximum operating conditions of multi-stage gasifiers depend on the equivalent ratio and percentage of air injection into the gasifier. The results of nhuchhen [27] reported that the optimum combination was achieved at a ratio of 100 and $80 \mathrm{l} / \mathrm{min}$ for pyrolysis and oxidation zones. However, until now there has been leak of research discussing about the effect of air injection ratio on the performance of gasifier.

Increased performance of multi-stage gasifiers because all the energy from fuel is utilized to the maximum (all components of the fuel decompose perfectly). Char and tar products decreased while permanent gas and water vapor increased. The perfect decomposition occurs due to temperature rise in all gasification zones: drying $200^{\circ} \mathrm{C}$, pyrolysis $400-725^{\circ} \mathrm{C}$, partial oxidation $750-1195^{\circ} \mathrm{C}$ and reduction of $650-950^{\circ} \mathrm{C}$. The change of heat reaction properties in the pyrolysis zone requires heat of $0.28 \mathrm{MJ} / \mathrm{kg}$ to release the heat energy of $7.23 \mathrm{MJ} / \mathrm{kg}$. The input of air in the reduction zone changes the nature of the charcoal layer into an activated carbon and is capable of capturing tar components. Equivalent ratio as control variables remain within the optimum range of 0.2-0.4 so that the heating value and cold gas efficiency are not decreased and even reach $7.88 \mathrm{MJ} / \mathrm{Nm}^{3}$ and $89.7 \%[12,13,14]$

This paper reports the results of experiments that have been carried out using a multi-stage downdraft gasifier to determine the effect of operating conditions (air ratio, equivalent ratio) to the gas composition, heating value, gasifier efficiency, and tar produced is also calculated. The aim of this study was to obtain optimum operating conditions that can have a significant influence to the performance of the gasifier.

\section{MATERIAL AND METHOD}

\section{Biomass Characterization}

Biomass used in this study is Pellet of Municipal Solid Waste Pellet with diameter of $7 \mathrm{~mm}$ and an average length of 10-15 mm. The advantage of using pellet when compared with briquettes and pieces are more uniform shape, its density is higher, and its LHV is greater. Moreover, it can eliminate the gaps between the layers of the fuel, thus simplifying the movement of fuel and gas flow through the layer. Analysis of ash content, volatile and fixed carbon content using elemental analysis (Carbon, Hydrogen, Nitrogen, Sulfur, Oxygen) and determination of the Lower Heating Value of biomass conducted at the Laboratory Institut Teknologi Sepuluh November LPPM. Result of fuel characterization shown at table 1.

\section{Gasification System}

Multi-stage gasifier has a length of 1.26 meters with an effective internal diameter of 0.5 meters. The inner insulation layer of the gasifier uses a refractory cement to minimize heat transfer. Grate is made using stainless steel plate with a thickness of $10 \mathrm{~mm}$. Important parts of this system are gasifier, fuel system, ash disposal, cooling system (water scrubber) and cleaning (cyclone, dry filter), blower, and induced draft fan. Initially this gasifier operated with a batch system, but in this study, was modified into a continuous system by adding a hopper and screw feeding. To maintain contact between fuel, air and gas are used continuously stirrers. Fuel consumption is measured on a scale of decline in fuel level sticks. The gasifier is divided into 3 parts, $600 \mathrm{~mm}$ for the hopper, 600 $\mathrm{mm}$ for the drying zone and pyrolysis, $300 \mathrm{~mm}$ for partial oxidation and $200 \mathrm{~mm}$ for the reduction zone and syngas space. The air input is at two points, first in the pyrolysis zone and second in the partial oxidation zone with four variation of Air Ratio (AR) $(0,70,80,90)$ and three condition of Equivalent Ratio (ER) $(0.3,0.4,0.5)$. Air out 
through the nozzle as much as 4 pieces for each level with a slope of $75^{\circ}$. The air supply is obtained from the blower and heated first using an induction heater to a temperature of $200^{\circ} \mathrm{C}$. The ash disposal mechanism uses a sweeper that rotates over the grate and ash is accommodated using an ash box. To draw air from gasifier to flare point in use Induced Draft Fan.

As fuel enters the gasifier through the screw feeder, the first zone through which drying is fueled still has moisture content undergoes a drying process and produces dry biomass and water vapor. Furthermore, drying products will experience a thermal decomposition process that occurs in the environment without oxygen and produce char products, volatile gas, and water vapor until the temperature reaches $500^{\circ} \mathrm{C}$. The product of the process then enters an oxidative pyrolysis zone where a small amount of air enters causing partial combustion of the charcoal and generates a certain amount of heat. The heat produced will cause the temperature rise to reach $700^{\circ} \mathrm{C}$ and decompose the tar formed in the pyrolysis zone of the primary tar into secondary tar. The amount of pyrolysis product increases because charcoal burning produces a certain amount of gas and inherent moisture biomass completely. Upon entering the oxidation zone there is a partial charcoal combustion process from the previous process, the heat generated from this zone is released to all the layers which require heat input (drying, pyrolysis, and reduction). Because the oxidative pyrolysis process also releases heat, the amount of heat released by the oxidation zone decreases so that the resulting reaction temperature increases. This increase in temperature is very good for thermal cracking process of tar content. The detail of schematic of gasification system are shown in Fig. 1

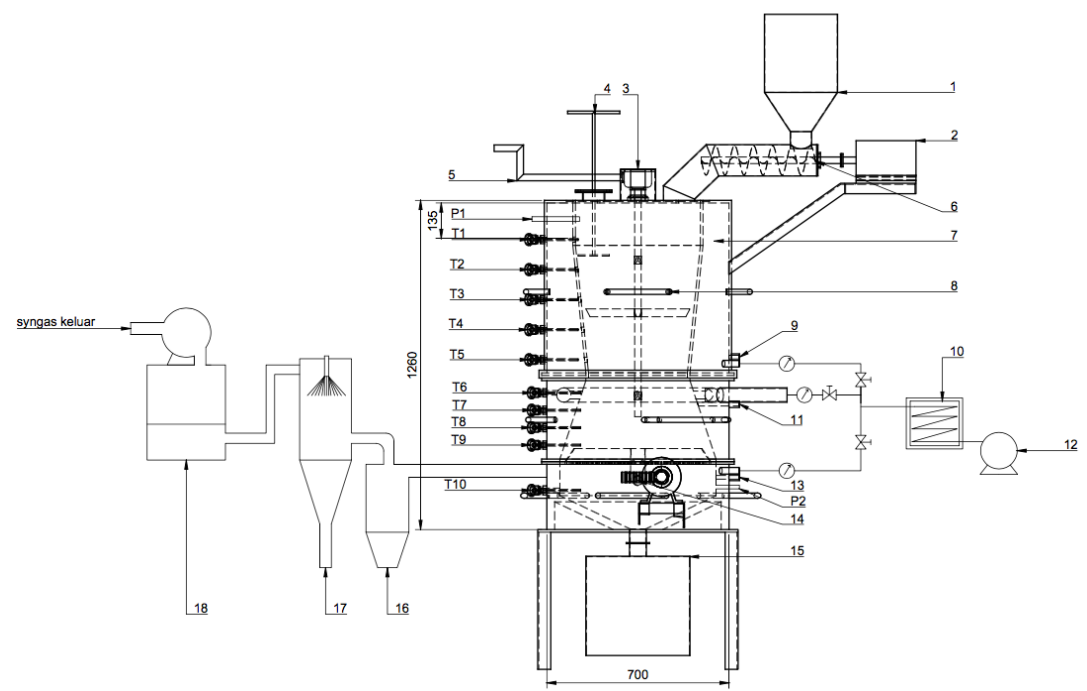

FIGURE 1. Schematic of Gasification System

1. Hopper; 2. Electric motor driving the screw feeder; 3. Speed reducers; 4. Fuel level Stick; 5. Arm stirrer; 6. Screw Feeder; 7. Refractory cement wall insulation; 8. Arm stirrer; 9. Sampling Port of pyrolysis zone; 10. Air Heater; 11. Sampling Port partial oxidation zone; 12. Blower; 13. Sampling Port reduction zone;

14. Grate sweep mechanism; 15. ash box; 16. Cyclone; 17. Water Scrubber; 18. Dry Filter

TABLE 1. Result of Fuel Characterization

\begin{tabular}{lc}
\hline Parameter & Value \\
\hline Proximate Analysis (wt. \%) & \\
Ash & 14.71 \\
Volatile Matter & 65.78 \\
Fixed Carbon & 9.69 \\
\hline Ultimate Analysis (wt. \%) & \\
Carbon & 39.83 \\
Hydrogen & 6.7 \\
Nitrogen & 0.35 \\
Sulfur & 0.14 \\
Oxygen & 38.11 \\
\hline
\end{tabular}




\section{RESULT AND DISCUSSION}

1. Temperature Profile

Based on Table 2 it can be observed that the use of multi-stage air inlet in the gasifier can increase the temperature in the pyrolysis zone to near partial oxidation temperatures. The mean temperatures in the pyrolysis zone are respectively between $569^{\circ} \mathrm{C}$ and $633^{\circ} \mathrm{C}$ for the $0 \%$ and $90 \%$ Air Ratios. While the temperature of the partial oxidation zone reaches $858^{\circ} \mathrm{C}$. This temperature rise shows the behavior of decreasing the amount of tar formed during the pyrolysis process and allows for the occurrence of thermal cracking processes in the partial oxidation process.

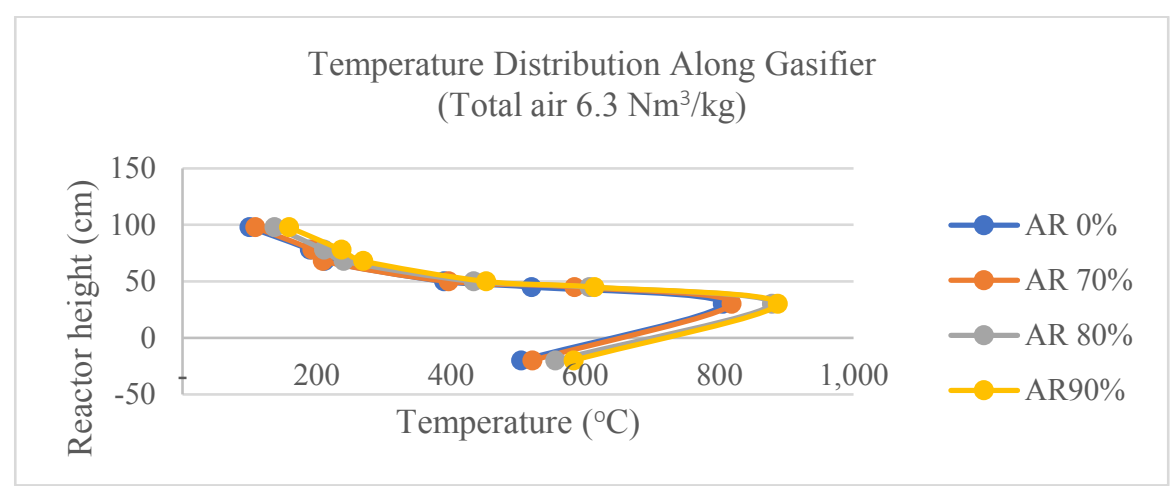

FIGURE 2. Temperature Distribution Along Gasifier (Total air $6.3 \mathrm{Nm}^{3} / \mathrm{Kg}$ )

As shown in Fig. 2, the pyrolysis zone and partial oxidation indicate an increase in mean temperature when the gasifier is operated under multi-stage conditions when compared to the temperature at a single stage (AR 0\%) condition. This temperature rise is due to the increase temperatures in the pyrolysis zone. When the gasifier is operated in a single stage, heat energy for the process is only produced from an exothermic partial combustion reaction. So, the heat energy for the drying zone, pyrolysis and reduction depends on the heat of the partial oxidation zone. When it operated in multi-stage conditions, in the pyrolysis zone changes the nature of the endothermal become exothermal. This means the zone no longer needs heat but releases heat. So, the amount of heat energy released by the partial oxidation zone becomes reduced and drives the temperature rise in the zone.

TABLE 2. Average Gasification Zone Temperature Distribution

\begin{tabular}{|c|c|c|c|c|c|c|c|c|c|c|c|c|}
\hline \multirow{2}{*}{$\begin{array}{l}\text { Total Air Injection } \\
\text { AR (\%) }\end{array}$} & \multicolumn{4}{|c|}{ 6,3 $\mathrm{Nm}^{3} / \mathrm{jam}$} & \multicolumn{4}{|c|}{$8,4 \mathrm{Nm}^{3} / \mathbf{j a m}$} & \multicolumn{3}{|c|}{$10,5 \mathrm{Nm}^{3} / \mathrm{jam}$} & \multirow[b]{2}{*}{90} \\
\hline & 0 & 70 & 80 & 90 & 0 & 70 & 80 & 90 & 0 & 70 & 80 & \\
\hline Drying & 100 & 108 & 137 & 158,5 & 110 & 122 & 157 & 177 & 143 & 169 & 195 & 219 \\
\hline Pyrolysis & 390 & 397 & 434 & 452 & 416 & 430 & 466 & 509 & 432 & 439 & 495 & 513 \\
\hline Oxidation & 805 & 818 & 878 & 887 & 820 & 823 & 892 & 893 & 833 & 839 & 904 & 913 \\
\hline Reduction & 505 & 521 & 556 & 583 & 515 & 525 & 590 & 608 & 532 & 538 & 590 & 596 \\
\hline
\end{tabular}

In Figure 2 it can be observed that the air at the pyrolysis zone causing the temperature increase in the drying zone up to $143^{\circ} \mathrm{C}$ that happened an initial early phase pyrolysis [15] and the pyrolysis temperature increase up to $500^{\circ} \mathrm{C}$. This temperature increase because oxygen into the pyrolysis zone and pyrolysis process occurs in an oxidative environment or also called oxidative pyrolysis. The entry of oxygen changes the pyrolysis properties of the endothermal into exothermic because at a temperature of $500^{\circ} \mathrm{C}$ the heat energy required for the pyrolysis process reaches the zero point (energy neutral point) and the pyrolysis process no longer needs heat but releases heat [16, 17]. 


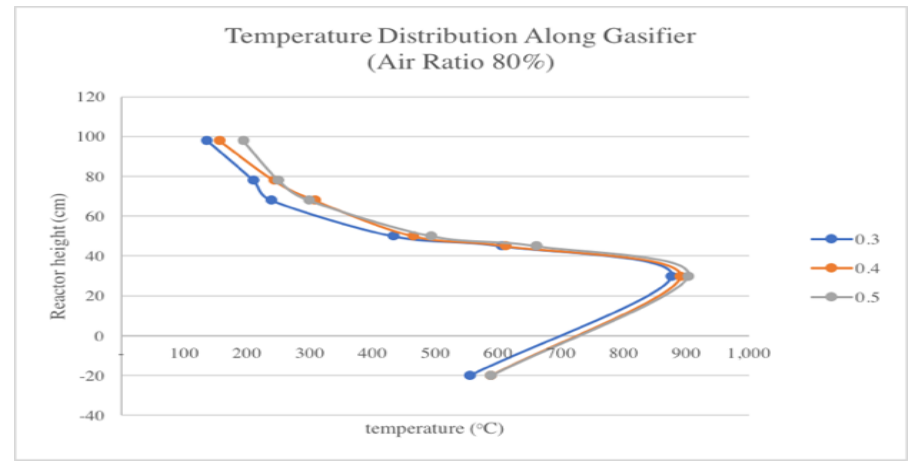

FIGURE 3. Effect of ER value to the Gasifier Temperature at Different Zone (Air Ratio 80\%)

When compared with an inert air (Air Ratio 0\%) pyrolysis reaction occurs in two stages, namely drying and volatile removal whereas oxidative conditions occuring in three stages, namely drying, volatile removal and char oxidation. In this condition, the amount of ash particles resulting lower when compared with inert condition [18]. Increasing temperatures in the drying zone affected the time to startup and evaporate the water content in the fuel becomes shorter. In Figure 3 it can be seen that the temperature increase occurs proportionally in each gasification zone (drying, pyrolysis, oxidation, reduction) along with the increase in AR and this condition can improve the process of tar cracking [11] especially at AR 90\% with oxidation temperature of $913^{\circ} \mathrm{C}$.

\section{Gas Composition and Low Heating Value (LHV)}

The gas compositions $\left(\mathrm{CO}, \mathrm{H}_{2}, \mathrm{CH}_{4}, \mathrm{CO}_{2}\right)$ were evaluated for each variation of air ratio $(0 \%, 70 \%, 80 \%, 90 \%)$. Figure 4 and 5 shown the concentration of the gas composition and its LHV. Based on figure 5, for ER $0.3-0.5$ with total air between $6.3 \mathrm{Nm}^{3} / \mathrm{h}$ up to $10.5 \mathrm{Nm}^{3} / \mathrm{h}$ indicates an increase gas composition and LHV at ER 0.4 and decrease on ER 0.5. The H2 content rises from 11.57\% (ER 0.3) to 14.24\% (ER 0.4) because of the occurrence of tar cracking [11] and signifies the reaction of water-gas shift occurs at high temperatures [14] then the $\mathrm{H}_{2}$ content decreases when ER 0.5 due to an increase in the hydrogen oxidation reaction.

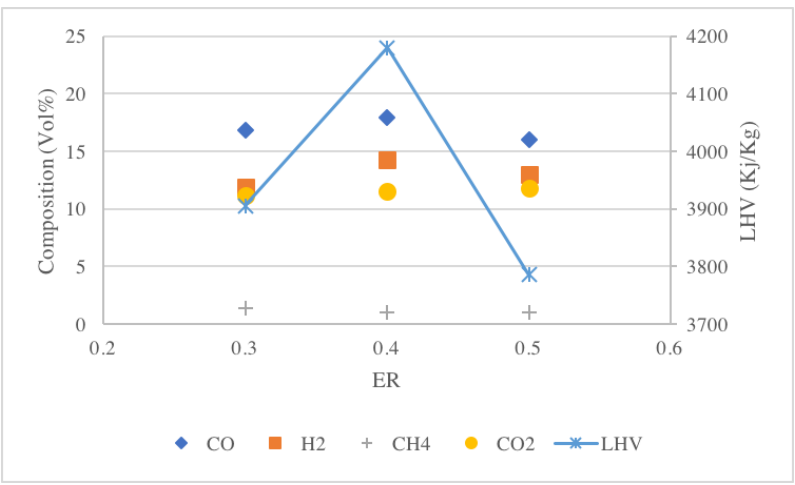

FIGURE 4. Effect of ER value to the Gasifier Temperature at Different Zone (Air Ratio 80\%)

Figure 5 shown the syngas composition based on the AR variation. When the percentage of AR increases the percentage of gas content and LHV also increased to $4.221 \mathrm{Kj} / \mathrm{Kg}$. The most dominant increase in syngas composition occurs at the pyrolysis stage where the amount of volatile gas $\left(\mathrm{CO}, \mathrm{CH}_{4}, \mathrm{CO}_{2}\right)$ of oxidative pyrolysis increases from $0.3 \mathrm{~g} / \mathrm{g}$ of biomass to $0.7 \mathrm{~g} / \mathrm{g}$ of biomass. $\mathrm{H}_{2}$ content also increase at oxidative conditions from $0.08 \%$ $\mathrm{g} / \mathrm{g}$ biomass to $0.15 \mathrm{~g} / \mathrm{g}$ biomass because of the amount of inherent moisture in the fuel entirely converted into water vapor [19].

In addition, the $\mathrm{CH}_{4}$ composition decreased with increasing ER because at high temperatures the hydrogasification reaction occurred more slowly [20]. When the ER rises to 0.5 the $\mathrm{CO}_{2}$ content increase followed by the temperature increase in the oxidation zone, this condition is favorable for the combustion process but $\mathrm{CO}, \mathrm{H}_{2}$ LHV composition decreases. The decrease in $\mathrm{CO}$ and increase of $\mathrm{CO}_{2}$ is due to the increase in the amount of 
combustion air approaching the stoichiometric state, while the expected gasification is the combustion reaction under stoichiometric conditions.

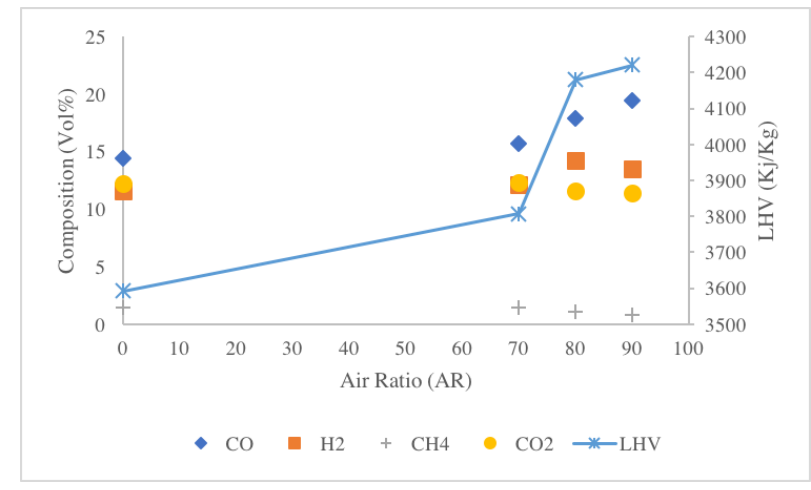

FIGURE 5. Effect of Air Ratio to the Syngas composition and LHV

\section{Tar Content}

Figure 7 shown the highest tar content obtained at ER 0.3 (total air $6.3 \mathrm{Nm} / \mathrm{h}$ ). This condition associated with low temperature in the pyrolysis zone below $500^{\circ} \mathrm{C}$. As for ER 0.4 and 0.5 pyrolysis temperature above $500^{\circ} \mathrm{C}$ till the pyrolysis process completed above this temperature and the primary tar will begin rearrange and formed a noncondensable gas and lighter molecular called secondary tar. So, when passing through the oxidation zone and undergo thermal cracking it will be formed lighter namely tertiary tar [15].

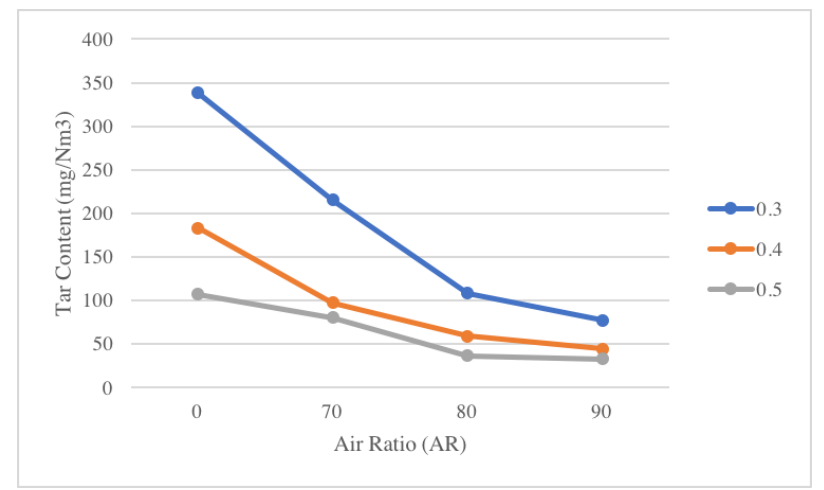

FIGURE 7. Effect of ER and AR to the tar content

Based on the figure 7 tar content decreased with the increase of AR to the greater. Air supplied into the gasifier reaction effected temperature increases and this condition is good for thermal cracking of tar and improve the composition of the combustible gas. This temperature increase due to the inclusion of air in the pyrolysis zone and that zone provide heat to the zone of oxidation and drying. The lowest tar content in gas is achieved when the gasifier is operated with ER 0.3 (total water $10.5 \mathrm{Nm} 3 / \mathrm{h}$ ) and air ratio (AR) $90 \%$.

\section{CONCLUSION}

Multi stage gasifier giving benefit for Utilization of the maximum energy of fuel because all components of the fuel can decompose perfectly into pyrolysis products namely char, permanent gas $\left(\mathrm{CO}_{2}, \mathrm{CH}_{4}, \mathrm{CO}, \mathrm{H}_{2}\right)$, water vapor and tar. Oxidation temperature also increases and it is very good for thermal cracking process pyrolysis products. Multi stage gasifiers can reduce the tar content in syngas due to temperatures increases in the pyrolysis zone and the oxidation zone. Temperature increases in the pyrolysis zone change the nature of the endothermal into exothermal and providing the heat energy for the drying, oxidation and reduction zones. Equivalent ratio is the most dominant 
variable affected to gasification operation. For multi-stage gasifiers, the determination of air ratio is based on the total air of the equivalent ratio. While the air ratio provides significant changes to the nature of the pyrolysis zone. For a total air flow of $10.5 \mathrm{Nm}^{3} / \mathrm{h}$ with a $90 \%$ air ratio, the gasifier can produce a low tar content of $32.27 \mathrm{mg} / \mathrm{Nm}^{3}$ when compared to $0 \%$ air ratio of $106.5 \mathrm{mg} / \mathrm{Nm}^{3}$. This result shown that multi-stage gasifier can reduce tar content by $30 \%$. The results presented in this study can be used as a reference to optimize the operation of multi-stage downdraft gasifier to produce greater efficiency.

\section{REFERENCE}

1. Asadullah, M. (2014). Barriers of commercial power generation using biomass gasification gas: a review. Renewable and Sustainable Energy Reviews, 29, 201-215.

2. Chiang, K. Y., Chien, K. L., \& Lu, C. H. (2012). Characterization and comparison of biomass produced from various sources: suggestions for selection of pretreatment technologies in biomass-to-energy. Applied Energy, 100, 164-171.

3. Son, Y. I., Yoon, S. J., Kim, Y. K., \& Lee, J. G. (2011). Gasification and power generation characteristics of woody biomass utilizing a downdraft gasifier. biomass and bioenergy, 35(10), 4215-4220.

4. Wongchanapai, S., Iwai, H., Saito, M., \& Yoshida, H. (2012). Performance evaluation of an integrated smallscale SOFC-biomass gasification power generation system. Journal of Power Sources, 216, 314-322.

5. Buragohain, B., Mahanta, P., \& Moholkar, V. S. (2010). Thermodynamic optimization of biomass gasification for decentralized power generation and Fischer-Tropsch synthesis. Energy, 35(6), 2557-2579

6. Molino, A., Giordano, G., Motola, V., Fiorenza, G., Nanna, F., \& Braccio, G. (2013). Electricity production by biomass steam gasification using a high efficiency technology and low environmental impact. Fuel, 103, 179192.

7. Bridgwater, A. V. (1995). The technical and economic feasibility of biomass gasification for power generation. Fuel, 74(5), 631-653

8. Bhattacharya, S. C., Siddique, A. M. M. R., \& Pham, H. L. (1999). A study on wood gasification for low-tar gas production. Energy, 24(4), 285-296.

9. Negro, S. O., Suurs, R. A., \& Hekkert, M. P. (2008). The bumpy road of biomass gasification in the Netherlands: Explaining the rise and fall of an emerging innovation system. Technological Forecasting and Social Change, 75(1), 57-77.

10. Devi L, Ptasinski KJ, Janssen FJJG. A review of the primary measures for tar elimination in biomass gasification processes. Biomass Bioenergy 2003;24:125-40.

11. Galindo, A. L., Lora, E. S., Andrade, R. V., Giraldo, S. Y., Jaén, R. L., \& Cobas, V. M. (2014). Biomass gasification in a downdraft gasifier with a two-stage air supply: Effect of operating conditions on gas quality. biomass and bioenergy, 61, 236-244.

12. Raman, P., Ram, N. K., \& Gupta, R. (2013). A dual fired downdraft gasifier system to produce cleaner gas for power generation: Design, development and performance analysis. Energy, 54, 302-314.

13. Martinez, J. D., Lora, E. E. S., Andrade, R. V., \& Jaén, R. L. (2011). Experimental study on biomass gasification in a double air stage downdraft reactor. Biomass and Bioenergy, 35(8), 3465-3480.

14. Jaojaruek, K., Jarungthammachote, S., Gratuito, M. K. B., Wongsuwan, H., \& Homhual, S. (2011). Experimental study of wood downdraft gasification for an improved producer gas quality through an innovative two-stage air and premixed air/gas supply approach. Bioresource technology, 102(7), 4834-4840.

15. P. Basu, Biomass Gasification and Pyrolysis Handbook. 2010.

16. Su, Y., Luo, Y., Wu, W., Zhang, Y., \& Zhao, S. (2012). Characteristics of pine wood oxidative pyrolysis: Degradation behavior, carbon oxide production and heat properties. Journal of Analytical and Applied Pyrolysis, 98, 137-143.

17. D. Li, F. Berruti, and C. Briens, "Autothermal fast pyrolysis of birch bark with partial oxidation in a fluidized bed reactor," Fuel, vol. 121, pp. 27-38, 2014

18. Chouchene, A., Jeguirim, M., Khiari, B., Zagrouba, F., \& Trouvé, G. (2010). Thermal degradation of olive solid waste: influence of particle size and oxygen concentration. Resources, Conservation and Recycling, 54(5), 271-277.

19. Zhao, S., Luo, Y., Su, Y., Zhang, Y., \& Long, Y. (2014). Experimental investigation of the oxidative pyrolysis mechanism of pinewood on a fixed-bed reactor. Energy \& Fuels, 28(8), 5049-5056. 
20. Guo, F., Dong, Y., Dong, L., \& Guo, C. (2014). Effect of design and operating parameters on the gasification process of biomass in a downdraft fixed bed: An experimental study. International Journal of Hydrogen Energy, 39(11), 5625-5633.

21. Sudarmanta, B., Murtadji, D. B., Wulandari, D. F., \& FTI-ITS, J. T. M (2009). Karakterisasi Gasifikasi Biomassa Sekam Padi Menggunakan Reaktor Downdraft dengan Dua Tingkat Laluan Udara.

22. Sudarmanta. B, (2002). Karakterisasi Gasifikasi Downdraft Berbahan Baku Cangkang Kelapa Sawit dengan Variasi Gasifying Agent. Research Gate.

23. Sudarmanta, B. (2015). Dual fuel engine performance using biodiesel and syn-gas from rice husk downdraft gasification for power generation. International Seminar on Sustainable Biomass Production and Utilization: Challenges and Oportunies.

24. Bui T, Loof R, Bhattacharya SC. Multi-stage reactor for thermal gasification of wood. Energy 1994;19(4):397704

25. Antonopoulos, I. S., Karagiannidis, A., Elefsiniotis, L., Perkoulidis, G., \& Gkouletsos, A. (2011). Development of an innovative 3-stage steady-bed gasifier for municipal solid waste and biomass. Fuel processing technology, 92(12), 2389-2396.

26. Bentzen, J. D., Henriksen, U. B., Hindsgaul, C., \& Brandt, P. (2000, June). Optimized two-stage gascifier. In 1st World Conference and Exhibition on Biomass for Energy and Industry.

27. Nhuchhen, D. R., \& Salam, P. A. (2012). Experimental study on two-stage air supply downdraft gasifier and dual fuel engine system. Biomass Conversion and Biorefinery, 2(2), 159-168. 